\title{
Review Article \\ Extreme Weather Events and Mental Health: Tackling the Psychosocial Challenge
}

\author{
Jyotsana Shukla \\ Amity Institute of Behavioral and Allied Sciences, Amity University, Lucknow 226010, India \\ Correspondence should be addressed to Jyotsana Shukla; jsreena@gmail.com
}

Received 24 May 2013; Accepted 12 June 2013

Academic Editors: E. Clays, S. M. Pezzotto, and I. Szadkowska-Stanczyk

Copyright (C) 2013 Jyotsana Shukla. This is an open access article distributed under the Creative Commons Attribution License, which permits unrestricted use, distribution, and reproduction in any medium, provided the original work is properly cited.

\begin{abstract}
Climate change is an emerging challenge to the mental health of entire humanity. Several studies, in recent times, have brought to light the adverse public mental health outcomes of extreme weather events for the suffering communities. The general public and the policy making bodies need to gain awareness about these impacts. Through such awareness, communities and their governments can institutionalize mechanisms to provide psychological support to the populations affected by climate change, before it becomes a massive public health challenge and starts affecting the social and vocational lives of people. There is an urgent need for addressing these impacts. The aim of this paper is to provide an overview of the deleterious effects of climate change related extreme weather events on mental health, the worldwide response of several communities to such events, and preparedness of the public and government to deal with these adverse mental health impacts. Policy imperatives to prevent and mitigate these impacts have been suggested. It is hoped that the psychologists, governments, and communities will act earnestly to prevent the impending harm to human mental health due to climate change.
\end{abstract}

\section{Introduction}

Climate change is conceived as a long-term change in the average weather of a particular location [1]. According to United Nations Framework Convention on Climate Change (article 1 [1]), climate change refers to change of climate that is attributed directly or indirectly to a clearly evident human activity, and which could be measured as well [2].

Despite awareness, there is a lot of antipathy as well as procrastination towards formulating policies to reign in climate change. Countries like US and UK are evading the issue of tackling climate change through reduced carbon emissions. Europe, while reiterating its commitment to reduce its carbon emissions significantly, continues to encourage emissions, by indulging in import of carbon intensive goods from overseas [3].

\section{Extreme Weather Events}

Global warming is increasing the rates of the earth's hydrological cycle, and as a result of which we are witnessing extreme weather events such as more intense, frequent, and lengthy periods of droughts, more news of cloud bursts, and heavy precipitation events, as well as the resultant flooding [4]. In recent times, we have seen large-scale flooding in Pakistan; landslides in China; heat, drought, and wildfires in Russia; and record floods and heat waves, hurricanes in the US, that have left deaths, destruction, and displacement, in their aftermath [5]. These disasters have been strongly related to global warming [6].

Climate change and health frameworks have recently started discussing about the psychological and mental health implications of climate change $[7,8]$. Disasters like tsunami and hurricane Katrina have brought mental health issues into the limelight [9]. The consequences of climate change can affect nearly every aspect of human life, including physical and mental health [10], in the form of maladaptive responses, such as trauma, chronic stress, anxiety or depressive disorders, comorbidity with existing psychopathology or medical illness, acting out, or other dysregulated defenses [11].

\section{Direct Impacts of Extreme Weather Events}

Climate change related extreme weather events may directly affect the spread and intensity of mental health problems in the affected communities and increase the responsibility of 
mental health institutions and systems. In the wake of climate related events, the social, economic, and environmental determinants of mental health, in vulnerable and affected communities, also get disrupted [12].

With the rising global temperatures, which is a climate related phenomenon, people with mental illness are at increased risk of heat-related deaths [13]. When heat waves happen, the populations may suffer heat strokes which may lead to delirium and neuropsychiatric syndromes with symptoms such as altered consciousness, agitation, restlessness, unconsciousness, and even death [14]. Moreover, it has been observed that persons with mental illness have greater vulnerability to a heat stroke [15]. Experimental and correlational research has shown that that there is a causal relationship between heat and violence and that rising global temperatures may be followed by an increase in incidents of violent aggression [16], as may be seen in increasing rates of assault, rape, robbery, burglary, and larceny due to more people getting outside their homes as a result of higher temperatures [17]. It may also be due to the fact that more stress hormones are released into the blood due to excessive exposure to heat [18].

"There's every reason to expect that climate change might increase people's tendencies to be more aggressive towards each other, and that might have impacts on mental health" [19]. Even domestic violence has been found to increase due to natural disasters resulting from frustration and anger related to these unexpected events [20].

Another phenomenon, that of "suicidal behaviors", may also be caused by increasing climate related uncertainty. The "phenomenon of farmers' suicides in India" due to drought [21] may be seen as typical of the impact of climate related extreme events in poor, agrarian economies [8]. One study from Italy also showed higher incidence of suicidal behaviors in the country's northern towns where there was significant climate variation [22].

An increase in alcohol and drug abuse may be another disaster related behavioral phenomenon [23]. Alcohol consumption and drug abuse may increase during periods of heat waves [24]. This observation is supported by statistics from Australia where higher rates of drug and alcohol abuse, violence, family breakups, and suicide have been seen after extreme weather events, especially in rural and semirural areas of Australia [25].

There may be additional indirect impacts from severe weather events. The physiological functioning of the human body may be affected. For example, a negative relationship has been observed between climate change related stress and glucose levels in the blood. In Type 2 diabetes cases, this stress influences glycemic control [26]. Dealing with repeated episodes of psychological stress related to climate change may also result in cardiovascular diseases [27].

\section{Adverse Mental Health: An Indirect Impact of Extreme Weather Events}

The indirect effects which may also be called psychosocial responses to disasters due to climate change manifest themselves in various forms. These responses are somewhat common across national and cultural boundaries [28]. There may be aggravation of chronic mental health problems due to disruptions caused to health care service delivery as a result of population displacement and infrastructure loss in the aftermath of a disaster [29].

Rates of hospital admission for mental health problems after such disasters may serve as one of the indicators of mental health impact of disasters. In one study in Adelaide, South Australia, from 1993 to 2006, a positive relationship between ambient temperature and hospital admissions for mental and behavioral disorders was reported. The higher the temperature the higher the admissions for organic mental illnesses like "dementia; mood (affective) disorders; neurotic, stress related, and somatoform disorders; disorders of psychological development; and senility." Mortalities due to these disorders also increased during heat waves in the age group of 65 to 74 years [30].

In an eleven-year study conducted in Israel, a higher number of schizophrenia and "schizoaffective" patients were admitted to hospitals in summer and fall, respectively, where in the mean monthly admission rates of Schizophrenia patients correlated with the mean maximal monthly environmental temperature. It could be concluded that a persistently high environmental temperature may be a contributing factor for aggravation of psychotic symptoms in schizophrenia patients [31]. In the sunnier months which had longer average length for a day, the admission rates were found to be higher for mania [32]. Such studies need to be conducted in other parts of the world, where temperatures have been rising over the past few decades.

Various other climatic variables like daily ambient temperature, relative humidity, atmospheric pressure, rainfall, and hours of sunshine also correlate with seasonal variations in bipolar disorder admissions [33-35].

In a survey of Asian Tsunami affected population, the incidence of moderate to severe form of mental disorders like anxiety, depression, phobic disorder, and adjustment disorder was to the extent of $30 \%-50 \%$ population. Hurricanes also result in high prevalence of psychiatric morbidity [36]. A survey of a probability sample of 1043 hurricane Katrina affected residents revealed that the 30 -day prevalence rate was $49.1 \%$ for anxiety-mood disorders and 26.4\% for Posttraumatic Stress Disorders (PTSD). The prevalence of PTSD and attempts at self-harm showed an actual increase, over time, in a long-term mental health impact study of Katrina on a representative sample of 815 prehurricane residents. Even two years after the hurricane, high mental morbidity was observed [37].

Severe flooding which may become more frequent due to global warning may result in mental health problems. A four-time higher risk of psychological distress on the 12item General Health Questionnaire was reported in southern England following severe flooding in the town of Lewes [38]. Flooding leads to tremendous loss to life and property, displacement, and other long-term harmful problems; however, the mental health impact of flooding has not been examined in many parts of the globe. Even after one year, around half the children and adolescents exposed to the "supercyclone" in the state of Orissa in India had reported symptoms of the 
posttraumatic stress disorder (PTSD) syndrome of varying severity even after one year [39]. Postdisaster studies on mental health variables need to be carried out whenever a disaster strikes in any part of the world. For this, institutional mechanisms involving psychologists and psychiatrists need to be incorporated in the disaster planning of every country.

Drought, another climate change related phenomenon, may be very agonizing and lead to several hardships. Drought may affect family relationships and lead to stress, worry, and an increase in the rate of suicides. Drought may result in loneliness and more work since fewer workers are ready to work, partners move off to a new place for additional income or for school needs, and families may not get the needed social support at these times [40].

Studies from tropical countries like India suggest an increased prevalence of acute psychosis following viral fever, especially in winter [41]. Schizophrenia and mood disorders have been associated with Borna virus infection outbreaks, obsessive compulsive disorders with streptococcal infections and cognitive impairment with algal toxins [42].

It can be concluded that people who already have schizophrenia or other serious psychological problems are likely to suffer most as a result of natural disasters and extreme weather events. In the wake of such events, people who already had mental illnesses may have much more difficulty in coping than the normal residents, and they may be already living in substandard housing [12], and these people definitely are in more need of help from the public and government.

\section{Extreme Weather Event Related Population Displacement: Adverse Impact on Mental Health}

It is feared that millions of people across the globe will be displaced as a result of extreme weather events and other climate change related phenomenon, for example, sea level rise, destruction of local economies, and resource in the near future $[43,44]$. This population displacement from climate change is projected to be 200 million people worldwide by 2050. The displaced population may have to suffer place based distress due to involuntary migration and may experience loss of connection to their home environments, a phenomenon referred as "Solastalgia" [45]. These "acts of nature" thus lead to mental health related problems, displacement of population, and civil strife [46], which need to be addressed by the policy makers.

In climate vulnerable coastal areas, the indigenous communities may face additional mental health consequences related to disruption to their traditional ways of living, damage caused to the significant cultural sites at these locations, and the possibility of relocation from their habitats [47].

It has been predicted that displacement of some climate vulnerable communities, mainly from rural communities, coastal areas, and the Torres Strait, in Australia, may increase in coming years. Such migrations result in the loss of population and community life and affect the mental health of the displaced population as well as of people left behind to live in the declining community [48]. These migrating communities are seen by those communities who receive them as a threat to their culture and as competitors of their natural or economic resources; thus, the migrants run the risk of increased exposure to cultural and racial discrimination in these communities and the resulting negative mental health impacts [44].

The psychological distress, loss, and displacement resulting from weather related violent conflict have been found to be associated with a wide range of mental health impacts including anxiety, depression, and PTSD [49]. According to a study, which compared Enso data, from 1950 to 2004, with the history for conflicts, in which at least 25 people were killed in a year, the likelihood of wars and conflicts increases twofold during years affected by the El Niño climate-warming phenomenon. The data included 175 countries and 234 conflicts. Half of these conflicts each caused more than 1,000 battle-related deaths. Although the team does not claim that the wars are started by weather alone, it did conclude El Niño may have played a role in 21 percent of civil wars worldwide over the past 50 years [50].

\section{Extreme Weather Events: Adverse Impact on Mental Health of Children}

It is feared that the future generations will react to climate change related information and understanding with feelings of despair [51]. Children are known to show much more severe distress after disasters than do adults [52]. Children are especially prone to predisaster anxiety and post-trauma illness, which may be either due to direct exposure to lifethreatening circumstances and likely separation from family and community supports, or due to "the reality of living with long term threat" [53].

In a survey of Australian children, researchers noted that "a quarter of children are so troubled about the state of the world that they honestly believe it will come to an end before they get older" [54].

It is the duty of governments and public and the educational institutions to propagate information about climate change in a manner acceptable and suited for the age of children and increase their mental well-being by preparing them physically and mentally to face these events. For this, changes in curriculum are required so as to include disaster preparedness as a necessary tool to be given in the hands of our children by the educational system. This will help protect our children from harmful mental health impacts of these events.

\section{Extreme Weather Events and Impact on Mental Health: The Moderating Variables}

An Australian study recently reported that an individual is more likely to be worried about climate change if the individual is a female, or of under 35 years of age, and if the individual has a "pro-environmental orientation" and is high on "future anxiety" [55]. 
From a psychological perspective, it is believed that the thoughts and emotions related to potential threat from climate change will probably be managed through "adaptive protection motivation systems" and will be reframed through "social comparison with others and selective information exposure" [56]. People may have feelings of distress and anxiety after a disaster experience. People may feel "scared, sad, depressed, numb, helpless and hopeless, frustrated or angry." If they feel that the problems they face are too difficult, they may cope by denying the existence of the problem or may unrealistically minimize the threat perceived by them. They may also get desensitized by becoming resigned to the situation and may adopt cynicism [57].

The intensity and severity of a traumatic experience during a disaster will determine the severity of the mental health symptoms. It is believed that between 25 and 50 percent of all those people who face an extreme weather event may have some harmful mental health consequences. The extent of the harm could depend on the age of the person, his/her coping capacity, and how far he/she stays form the site of the disaster $[58,59]$.

Estimates of personal risk and attributions as to who is responsible for the disaster, for example, the cognitive appraisals of the people who face the extreme weather related events, may have an impact on the concern about climate change [60].

How people will respond to a disaster also depends on the media's role in providing information to people regarding the availability of psychological counseling and how to avail it [10].

If the populations affected by disaster are disadvantaged socioeconomically or are unemployed, then they run greater psychosocial risks of loss of personal freedom, have more negative perceptions about self, and may have feelings of stress, insecurity, and seclusion [61-63].

\section{The Emerging Psychosocial Challenge}

After an extreme weather event, or other natural disasters, there are other constraints such as lack of resources and skills to deal with the challenge, including the immediate chaos and extensive distress in the affected people [64].

Of greater concern is the fact that, at such times, the available mental health services for people already having mental disorders are disrupted and the new cases that emerge after a disaster remain untreated for a long while. It can be said that even the countries which have well-established mental health services lack disaster preparedness to deal with the mental challenge posed after disaster [65-67].

There is speculation that as a result of climate change related mental health challenges emerging after a disaster, pharmaceuticals companies may come up with new drugs. Some of these drugs could lead to extreme violent events, such as shootings and violence in future [68].

There is a need to deliberate on measures through which we can prevent and mitigate the sufferings related to extreme weather events and to help the public adapt to such eventualities $[1,69]$. Increasingly, government and various relief and aid agencies are emphasizing psychological and psychosocial support and interventions as a part of their overall response to disasters and other climate related emergencies [70]. During the Asian countries' response to Tsunami, mental health and psychosocial services received due attention and emergency mental health services were a part of the disaster emergency services [71]. Countries, across the globe, need to be prepared with these services to meet with the psychosocial consequences of these extreme events.

The success of the mental health services in dealing with the impacts of climate change, in the long run, will depend upon the availability of skilled manpower and the extent to which these services are brought into the fold of related services [72], such as private and public health services, aid organizations, and the government agencies which deliver essential services.

Quick evacuation from a disaster facing area may also help in mitigating the mental health sufferings of people living in its vicinity $[58,59]$. If we are prepared for the severe weather, there is bound to be less anxiety. It has been found that for families and children who are prepared for disaster emergencies, there is less anxiety [73]. It definitely pays to plan and be prepared for extreme weather events.

There is a realization that behavioral changes also need to be brought about in order to meet the climate change challenge. Psychologists have not yet understood what these behavioral changes are going to be [74], yet they are in agreement that day to day changes in behavior can lead to positive changes, on an extensive scale, in the long run. Thus, there is a need to emphasize behavioral changes regarding how we consume the earth's resources and the risks involved in overusing or abusing these resources.

We need to pay attention to the consumption patterns, risk perceptions, and the emotions related to climate change, as these are very important factors in preventing and containing the threat to climate across the globe [75].

There is an evident need to include social science and behavioral science research within climate change research, so that needed mental health services and help could be made available on time, then and there, following any population shifts that could arise as per projections of climate change research [76].

\section{The Role of Psychologists}

In order to address the direct and acute mental health consequences of extreme weather events resulting from climate change, the psychologists may be guided by the findings of disaster psychology and should aim at improving the long-term psychosocial adjustment of the affected people. To address the indirect mental health impacts of climate change, psychologists can employ individual and group therapies for those affected [10]. The therapy they will use may depend on the clinical picture presented by the affected cases and the adherence of the concerned psychologist towards any of the therapeutic schools, such as "eco-psychology, grief/loss counseling, cognitive behavioral therapy, and interpersonal therapies, and group therapy" [11]. 
Psychologists can also intervene by providing life skill based training through "mitigation and adaptation behaviors" training, so as to increase the coping capacities of populations facing the mental health impacts of climate change [10].

The government, public, and psychologists need to follow the findings and projections of climate change research with interest and purpose to prepare their capacities and skills, beforehand, in order to face the challenges that will be posed to them, as projected by these researches.

The governments need to be prepared for mental health challenges of climate change related disasters, and they need to look at these as investments and as preventive and mitigating measures. Additionally, the governments can continue to focus on pollution control and switching to cleaner energy options. They also need to encourage research that looks at the mental health impacts of climate change on society. At the same time, there is the need to address the mental health impacts of disasters that have already happened [77].

There is a tremendous effort required from psychologists and behavioral scientists. They need to be future oriented and prepared in order to deal with this mental health challenge. Psychologists need to start organizing themselves into "ready to respond" teams in case of climate related extreme disasters causing mental health problems. They also need to address the free floating anxiety and worry of the general population related to actual and projected climate change related extreme disasters happening across the globe. Government and community initiatives need to be taken on a large scale to institutionalize the mechanisms for psychological support, along with other socioeconomic measures, for dealing effectively with the actual and projected climate related adverse mental health impacts.

\section{References}

[1] R. S. Kovats, B. Menne, A. J. McMichael, C. Corvalan, and R. Bertollini, Climate Change and Human Health: Impact and Adaptation, WHO, Geneva, Switzerland, 2000.

[2] UNFCCC, New York, NY, USA, 1992, http://untreaty.un.org/ cod/avl/ha/ccc/ccc.html.

[3] T. Levitt, "The psychology of climate change: it's in my backyard now," 2012, http://www.chinadialogue.net/article/show/single/ en/5357-The-psychology-of-climate-change-it-s-in-my-backyard-now.

[4] IPCCa. Institute of Medicine (US) Forum on Microbial Threats, Global Climate Change and Extreme Weather Events: Understanding the Contributions to Infectious Disease Emergence: Workshop Summary, National Academies Press, Washington, DC, USA, 2008, http://www.ncbi.nlm.nih.gov/books/ NBK45737/.

[5] Union of Concerned Scientists, Climate Change and Mental Health: Extreme Weather Takes a Toll, Union of Concerned Scientists, Cambridge, Mass, USA, 2010, http://www.ucsusa .org/global_warming/science_and_impacts/impacts/climatechange-and-mental-health.html.

[6] Tech. Rep., A Climate of Suffering: The Real Costs of Living with Inaction on Climate Change Spotlight Report, 2011, http://www.climateinstitute.org.au/articles/publications/a-cli- mate-of-suffering-the-real-costs-of-living-with-inaction-onclimate-change.html.

[7] J. Lee, Climate Change and Equity in Victoria, Friends of the Earth, Melbourne, Australia, 2007.

[8] H. Berry, B. Kelly, I. Hanigan, A. McMichael, J. Welsh, and T. Kjellstrom, Rural Mental Health Impacts of Climate Change. Garnaut Climate Change Review, 2008.

[9] P. K. Chand and P. Murthy, Regional Health Forum - Volume 12, Number 1, 45. Climate Change and Mental Health, 2008.

[10] L. Karlsson, Climate Change Adaptation White Paper Series, Vermont Climate Change Health Effects Adaptation, Vermont Department of Health, May 2011, http://www.anr.state.vt.us/ anr/climatechange/Pubs/VTCCAdaptHealthEffects\%20.pdf.

[11] T. J. Doherty and S. D. Clayton, "The psychological impacts of global climate change," American Psychologist, vol. 66, no. 4, pp. 265-276, 2011.

[12] J. C. Fritze, G. A. Blashki, S. Burke, and J. Wiseman, "Hope, despair and transformation: climate change and the promotion of mental health and wellbeing," International Journal of Mental Health Systems, vol. 2, article 13, 2008.

[13] L. A. Page and L. M. Howard, "The impact of climate change on mental health (but will mental health be discussed at Copenhagen?)," Psychological Medicine, vol. 40, no. 2, pp. 177$180,2010$.

[14] World Health Organization, Mental Health Assistance to Population Affected by the Tsunami in Asia, WHO, Geneva, Switzerland, 2008, http://www.who.int/mental_health/resources/tsunami/en/indexl.html.

[15] M. P. Naughton, A. Henderson, M. C. Mirabelli et al., "Heatrelated mortality during a 1999 heat wave in Chicago," American Journal of Preventive Medicine, vol. 22, no. 4, pp. 221-227, 2002.

[16] C. A. Anderson, "Heat and violence," Current Directions in Psychological Science, vol. 10, no. 1, pp. 33-38, 2001.

[17] J. Rotton and E. G. Cohn, "Global warming and U.S. crime rates: an application of routine activity theory," Environment and Behavior, vol. 35, no. 6, pp. 802-825, 2003.

[18] J. Simister and C. Cooper, "Thermal stress in the U.S.A.: effects on violence and on employee behaviour," Stress and Health, vol. 21, no. 1, pp. 3-15, 2005.

[19] Z. Rehman, “Climate change impact on mental health," Daily Star, 2009, http://www.ecademy.com/node.php?id=155110.

[20] U. Irfan, Health: Researchers Warn of Climate Change Impacts on Mental Well-Being, E\&E Reporter, 2011, http://www.eenews.net/ stories/1059956405.

[21] Tata Institute of Social Sciences, "Causes of farmer suicides in Maharashtra: an enquiry," 2005, http://www.tiss.edu/Causes\% 20of\%20Farmer\%20Ssuicides\%20in\%20Maharashtra.pdf.

[22] A. Preti and P. Miotto, "Seasonality in suicides: the influence of suicide method, gender and age on suicide distribution in Italy," Psychiatry Research, vol. 81, no. 2, pp. 219-231, 1998.

[23] S. B. Math, S. C. Girimaji, V. Benegal, G. S. Uday Kumar, A. Hamza, and D. Nagaraja, "Tsunami: psychosocial aspects of Andaman and Nicobar islands. Assessments and intervention in the early phase," International Review of Psychiatry, vol. 18, no. 3, pp. 233-239, 2006.

[24] A. Bulbena, L. Sperry, and J. Cunillera, "Psychiatric effects of heat waves," Psychiatric Services, vol. 57, no. 10, p. 1519, 2006.

[25] The Independent, "Climate change threatens mental health too: study," August 2011, http://www.independent.co.uk/life-style/ health-and-families/climate-change-threatens-mental-healthtoo-study-2346415.html. 
[26] R. S. Surwit, M. A. L. van Tilburg, N. Zucker et al., "Stress management improves long-term glycemic control in type 2 diabetes," Diabetes Care, vol. 25, no. 1, pp. 30-34, 2002.

[27] P. H. Black and L. D. Garbutt, "Stress, inflammation and cardiovascular disease," Journal of Psychosomatic Research, vol. 52, no. 1, pp. 1-23, 2002.

[28] K. Rao, "Psychosocial support in disaster-affected communities," International Review of Psychiatry, vol. 18, no. 6, pp. 501505, 2006.

[29] Climate Change and Public Health, "Health effects," 2010, http://www.cdc.gov/climateandhealth/effects/default.htm.

[30] A. Hansen, P. Bi, M. Nitschke, P. Ryan, D. Pisaniello, and G. Tucker, "The effect of heat waves on mental health in a temperate Australian City," Environmental Health Perspectives, vol. 116, no. 10, pp. 1369-1375, 2008.

[31] R. Shiloh, A. Shapira, O. Potchter, H. Hermesh, M. Popper, and A. Weizman, "Effects of climate on admission rates of schizophrenia patients to psychiatric hospitals," European Psychiatry, vol. 20, no. 1, pp. 61-64, 2005.

[32] P. A. Carney, C. T. Fitzgerald, and C. E. Monaghan, "Influence of climate on the prevalence of mania," British Journal of Psychiatry, vol. 152, pp. 820-823, 1988.

[33] D. Mawson and A. Smith, "Relative humidity and manic admissions in the London area," British Journal of Psychiatry, vol. 138, no. 2, pp. 134-138, 1981.

[34] F. A. Abdul-Rahim, A. Al-Sabai, A. R. Al-Hamad, and E. Bamgboye, "The seasonality of mania: preliminary findings," Annals of Saudi Medicine, vol. 12, no. 5, pp. 472-475, 1992.

[35] E. Salib and N. Sharp, "Relative humidity and affective disorders," International Journal of Psychiatry in Clinical Practice, vol. 6, no. 3, pp. 147-153, 2002.

[36] "Tsunami wreaks mental health havoc," Bulletin of the World Health Organization, vol. 83, no. 6, pp. 401-480, 2005.

[37] R. C. Kessler, S. Galea, M. J. Gruber, N. A. Sampson, R. J. Ursano, and S. Wessely, "Trends in mental illness and suicidality after Hurricane Katrina," Molecular Psychiatry, vol. 13, no. 4, pp. 374384, 2008.

[38] S. Jain, P. Murthy, and S. K. Shankar, "Neuropsychiatric perspectives from nineteenth-century India: the diaries of Dr Charles I. Smith," History of Psychiatry, vol. 12, no. 48, part 4, pp. 459-466, 2001.

[39] P. Y. Collins, V. K. Varma, N. N. Wig, R. Mojtabai, R. Day, and E. Susser, "Fever and acute brief psychosis in urban and rural settings in north India," British Journal of Psychiatry, vol. 174, pp. 520-524, 1999.

[40] M. Reacher, K. McKenzie, C. Lane et al., "Health impacts of flooding in Lewes: a comparison of reported gastrointestinal and other illness and mental health in flooded and non-flooded households," Communicable Disease and Public Health, vol. 7, no. 1, pp. 39-46, 2004.

[41] N. Kar, P. K. Mohapatra, K. C. Nayak, P. Pattanaik, S. P. Swain, and H. C. Kar, "Post-traumatic stress disorder in children and adolescents one year after a super-cyclone in Orissa, India: exploring cross-cultural validity and vulnerability factors," BMC Psychiatry, vol. 7, article 8, 2007.

[42] G.-M. Sartore, B. Kelly, and H. J. Stain, "Drought and its effect on mental health-how GPs can help," Australian Family Physician, vol. 36, no. 12, pp. 990-993, 2007.

[43] O. Brown, Migration and Climate Change, International Organisation for Migration, Geneva, Switzerland, 2008.
[44] N. Myers, Environmental Refugees: An Emergent Security Issue, Economic Forum, Prague, Czech Republic, 13th edition, 2005.

[45] Center for Disease Control and Prevention, Mental Health and Stress-Related Disorders, Impacts on Risk, 2010, http://www.cdc.gov/climatechange/effects/mental_health.htm.

[46] H. Frumkin, J. Hess, G. Luber, J. Malilay, and M. McGeehin, "Climate change: the public health response," American Journal of Public Health, vol. 98, no. 3, pp. 435-445, 2008.

[47] D. Green, How Might Climate Change Affect Island Culture in the Torres Straight? CSIRO Marine and Atmospheric Research Paper 011, Commonwealth Scientific and Industrial Research Organisation (CSIRO), Canberra, Australia, 2006.

[48] C. Fraser, H. Jackson, F. Judd et al., "Changing places: the impact of rural restructuring on mental health in Australia," Health and Place, vol. 11, no. 2, pp. 157-171, 2005.

[49] World Health Organisation, World Report on Violence and Health, WHO, Geneva, Switzerland, 2002.

[50] M. McCarthy, "New study shows stark correlation between the fluctuations of El Niño and the incidence of civil conflicts," 2011, http://www.independent.co.uk/environment/climatechange/revealed-climate-quirk-that-doubles-risk-of-war2343243.html.

[51] R. F. Kefford, "Medical heat for climate change," The Medical Journal of Australia, vol. 184, no. 11, p. 582, 2006.

[52] World Health Organisation (WHO), Mental Health in Emergencies: Psychological and Social Aspects of Health of Populations Exposed to Extreme Stressors, World Health Organisation, Geneva, Switzerland, 2003.

[53] L. Goldwert, "Climate change threatens mental health too: study; Droughts, floods have psychological impact," Daily News, September 2011, http://www.nydailynews.com/life-style/ health/violent-weather-threatens-mental-health-study-article1.953454 .

[54] J. Tucci, J. Mitchell, and C. Goddard, Children's Fears, Hopes and Heroes: Modern Childhood in Australia, Australian Childhood Foundation, Melbourne, Australia, 2007.

[55] K. Searle and K. Gow, "Do concerns about climate change lead to distress?" International Journal of Climate Change Strategies and Management, vol. 2, no. 4, pp. 362-379, 2010.

[56] J. Reser, "The experience of natural disasters: psychological perspectives and understanding," in International Perspectives on Natural Disasters: Occurrence, Mitigation, and Consequences, J. P. Stoltman, J. Lidstone, and L. M. DeChano, Eds., pp. 369384, Kluwer Academic Publishers, Dordecht, The Netherlands, 2004.

[57] Australian Psychological Society (APS), Tip Sheet: Climate Change-What You Can Do, Australian Psychological Society, Melbourne, Australia, 2007.

[58] C. F. Weems, S. E. Watts, M. A. Marsee et al., "The psychosocial impact of Hurricane Katrina: contextual differences in psychological symptoms, social support, and discrimination," Behaviour Research and Therapy, vol. 45, no. 10, pp. 2295-2306, 2007.

[59] C. F. Weems, A. A. Pina, N. M. Costa, S. E. Watts, L. K. Taylor, and M. F. Cannon, "Predisaster trait anxiety and negative affect predict posttraumatic stress in youths after hurricane Katrina," Journal of Consulting and Clinical Psychology, vol. 75, no. 1, pp. 154-159, 2007.

[60] A. Leiserowitz, "Communicating the risks of global warming: American risk perceptions, affective images, and interpretive communities," in Creating a Climate for Change, S. C. Moser and 
L. Dilling, Eds., pp. 44-63, Cambridge University Press, New York, NY, USA, 2007.

[61] V. Patel, R. Araya, M. de Lima, A. Ludermir, and C. Todd, "Women, poverty and common mental disorders in four restructuring societies," Social Science and Medicine, vol. 49, no. 11, pp. 1461-1471, 1999.

[62] R. Wilkinson and M. Marmot, Social Determinants of Health: The Solid Facts, World Health Organisation, Geneva, Switzerland, 2nd edition, 2003.

[63] M. Shields and S. Price, "Exploring the economic and social determinants of psychological and psychosocial health," Discussion Paper 396, Institute for the Study of Labour, Bonn, Germany, 2001.

[64] H. T. Keenan, S. W. Marshall, M. A. Nocera, and D. K. Runyan, "Increased incidence of inflicted traumatic brain injury in children after a natural disaster," American Journal of Preventive Medicine, vol. 26, no. 3, pp. 189-193, 2004.

[65] P. S. Wang, M. J. Gruber, R. E. Powers et al., "Disruption of existing mental health treatments and failure to initiate new treatment after Hurricane Katrina," American Journal of Psychiatry, vol. 165, no. 1, pp. 34-41, 2008.

[66] P. Jull, The Politics of Northern Frontiers in Australia, Canada, and Other 'First World' Countries: A Discussion Paper, North Australian Research Unit, Australian National University, Darwin, Australia, 1991.

[67] S. A. Morrissey, Seasonal affective disorder: characteristics and prevalence in North Queensland [Ph.D. thesis], James Cook University of North Queensland, Townsville, Australia, 1995.

[68] M. Adams, "Climate change said to harm the mentally ill and cause more mental illness," 2009, http://www.naturalnews.com/ 027712_climate_change_mental_illness.html.

[69] J. A. Patz, M. A. McGeehin, S. M. Bernard et al., "The potential health impacts of climate variability and change for the United States: executive summary of the report of the health sector of the U.S. National Assessment," Environmental Health Perspectives, vol. 108, no. 4, pp. 367-376, 2000.

[70] C.-J. Kuo, H.-S. Tang, C.-J. Tsay, S.-K. Lin, W.-H. Hu, and C.C. Chen, "Prevalence of psychiatric disorders among bereaved survivors of a disastrous earthquake in Taiwan," Psychiatric Services, vol. 54, no. 2, pp. 249-251, 2003.

[71] J. I. Ruzek, B. H. Young, M. J. Cordova, and B. W. Flynn, "Integration of disaster mental health services with emergency medicine," Prehospital and Disaster Medicine, vol. 19, no. 1, pp. 46-53, 2004.

[72] J. Spickett, H. Brown, and D. Katscherian, Health Impacts of Climate Change: Adaptation Strategies for Western Australia, Department of Health, Perth, Australia, 2008.

[73] J. D. Osofsky, H. J. Osofsky, and W. W. Harris, "Katrina's children: social policy considerations for children in disasters," Social Policy Report, vol. 21, no. 1, pp. 3-20, 2007.

[74] A. Corner, "Psychology is the missing link in the climate change debate," Guardian, 2009, http://www.guardian.co.uk/environment/cif-green/2009/oct/26/psychology-of-climate-change.

[75] PsySR, "Climate Change and Mental Health: The Dramatic and Damaging Connections," PsySR's Program on Climate Change, Sustainability, and Psychology, Washington, DC, USA, 2010, http://www.psysr.org/about/programs/climate/PSYSR_Climate_Change_and_Mental_Health-Dramatic_and_Damaging Connections.pdf.

[76] C. Crowley, "The mental health needs of refugee children: a review of literature and implications for nurse practitioners,"
Journal of the American Academy of Nurse Practitioners, vol. 21, no. 6, pp. 322-331, 2009.

[77] The Climate Institute, A Climate of Suffering: The Real Cost of Living with Inaction on Climate Change, The Climate Institute, Melbourne, Australia, 2011. 


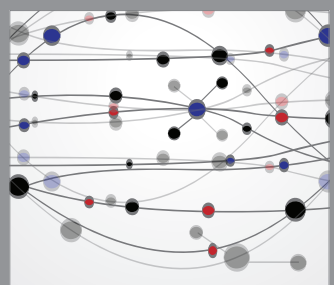

The Scientific World Journal
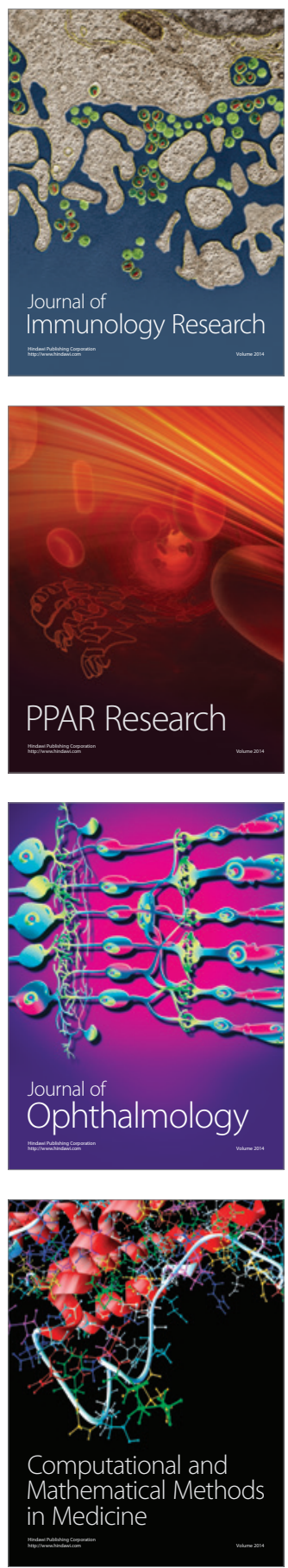

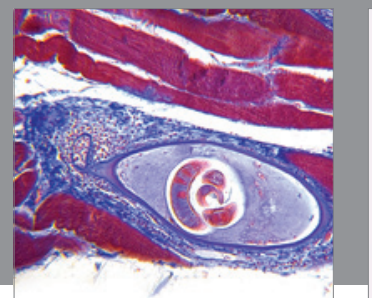

Gastroenterology

Research and Practice
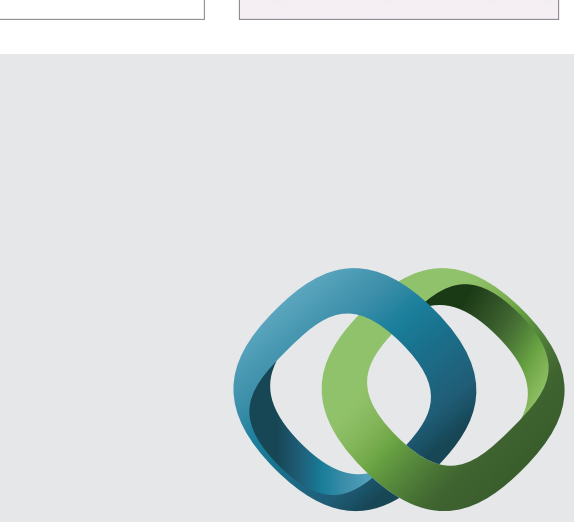

\section{Hindawi}

Submit your manuscripts at

http://www.hindawi.com
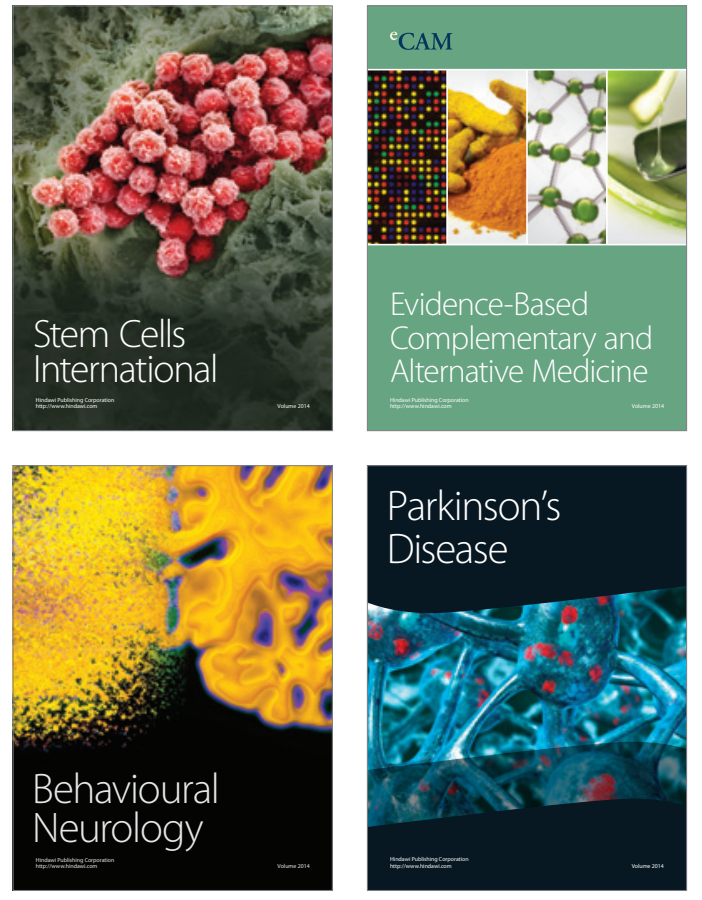
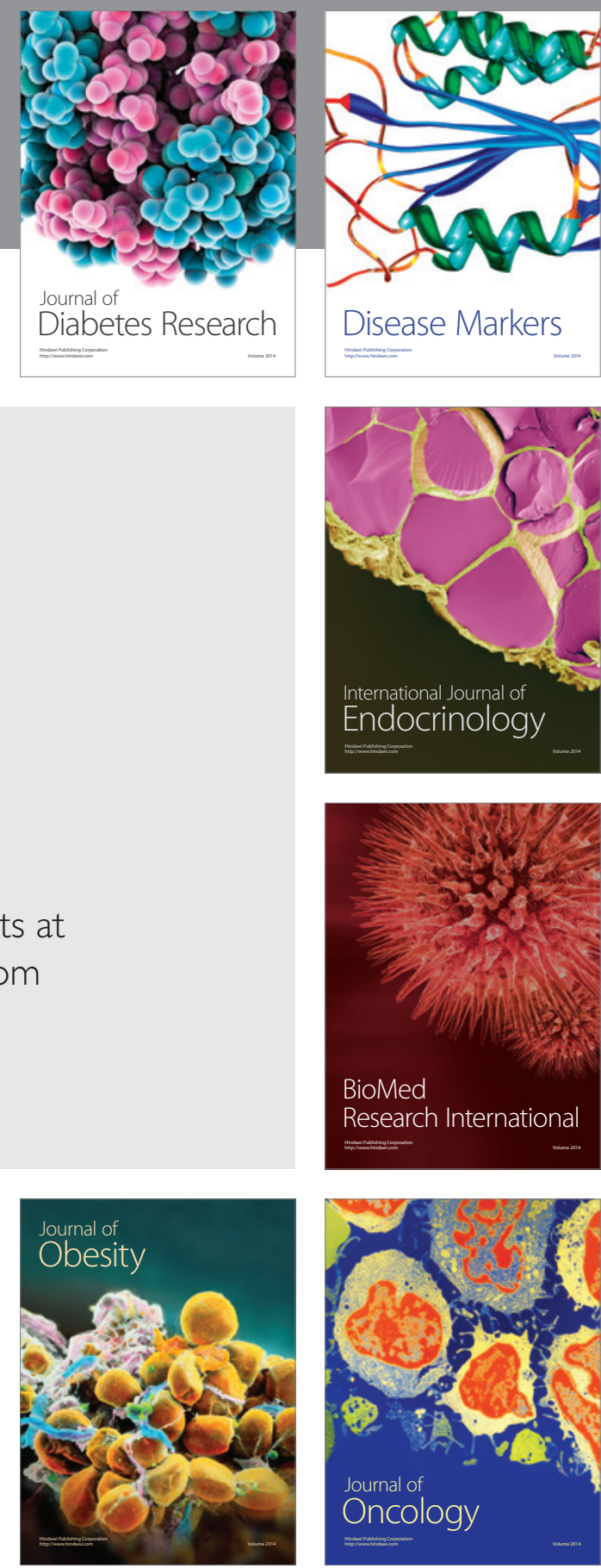

Disease Markers
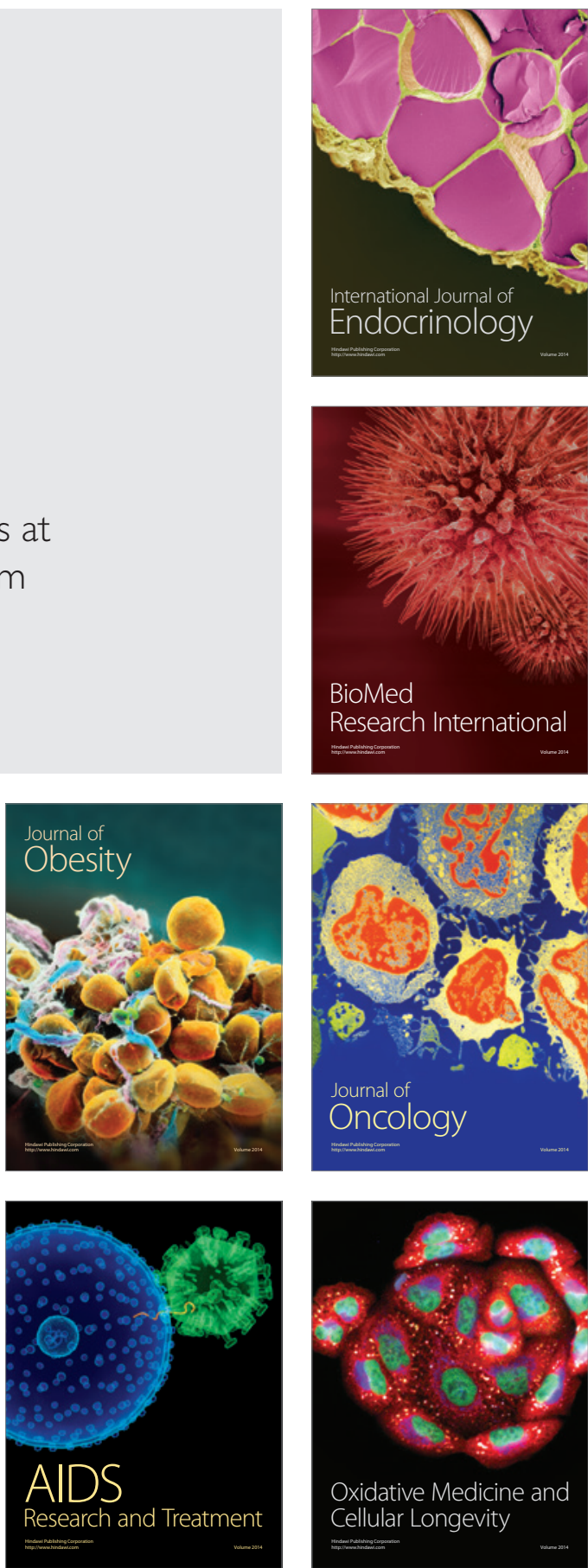